\title{
A Demographic Model to Evaluate Population Declines in the Endangered Streaked Horned Lark
}

\section{Modèle démographique visant à évaluer le déclin de l'Alouette hausse-col de la sous-espèce strigata, en voie de disparition}

\author{
$\underline{\text { Alaine F. Camfield }}^{1,2}, \underline{\text { Scott F. Pearson }}^{3}$, and $\underline{\text { Kathy Martin }}^{1,4}$
}

\begin{abstract}
The Streaked Horned Lark (Eremophila alpestris strigata) is listed as endangered by the State of Washington, USA and by Canada under the Species at Risk Act and is also classified as a federal candidate for listing under the Endangered Species Act in the USA. A substantial portion of Streaked Horned Lark habitat has been lost or degraded, and range contraction has occurred in Oregon, Washington, and British Columbia. We estimate the vital rates (fecundity, adult and juvenile survival) and population growth rate $(\lambda)$ for Streaked Horned Larks breeding in Washington, USA and conduct a Life-Stage Simulation Analysis (LSA) to evaluate which vital rate has the greatest influence on $\lambda$. We simulated changes in the three vital rates to examine how much they would need to be adjusted either independently or in concert to achieve a stable Streaked Horned Lark population $(\lambda=1)$. We also evaluated which fecundity component (the number of fledglings per egg laid or renesting interval) had the greatest impact on $\lambda$. The estimate of population growth suggests that Streaked Horned Larks in Washington are declining rapidly $(\lambda=0.62 \pm 0.10)$ and that local breeding sites are not sustainable without immigration. The LSA results indicate that adult survival had the greatest influence on $\lambda$, followed by juvenile survival and fecundity. However, increases in vital rates led to $\lambda=1$ only when adult survival was raised from 0.47 to 0.85 , juvenile survival from 0.17 to 0.58 , and fecundity from 0.91 to 3.09 . Increases in breeding success and decreases in the renesting interval influenced $\lambda$ similarly; however, $\lambda$ did not reach 1 even when breeding success was raised to $100 \%$ or renesting intervals were reduced to 1 day. Only when all three vital rates were increased simultaneously did $\lambda$ approach 1 without requiring highly unrealistic increases in each vital rate. We conclude that conservation activities need to target all or multiple vital rates to be successful. The baseline data presented here and subsequent efforts to manage Streaked Horned Larks will provide valuable information for management of other declining Horned Lark subspecies and other grassland songbirds across North America.
\end{abstract}

RÉSUMÉ. L'Alouette hausse-col de la sous-espèce strigata (Eremophila alpestris strigata) est désignée en voie de disparition dans l'État de Washington (États-Unis) et au Canada en vertu de la Loi sur les espèces en péril; elle est aussi inscrite comme espèce candidate en vertu de la loi fédérale sur les espèces menacées aux États-Unis. L'habitat de l'Alouette hausse-col de la sous-espèce strigata a subi des pertes et des dégradations considérables, et une contraction de la répartition a été observée en Oregon, dans l'État de Washington et en Colombie-Britannique. Nous avons estimé les taux vitaux (fécondité, survie des adultes et des jeunes) et le taux de croissance de la population $(\lambda)$ de l'Alouette hausse-col de la sous-espèce strigata nichant dans l'État de Washington, et avons effectué une simulation des stades du cycle vital afin d'évaluer quel taux vital a le plus grand effet sur $\lambda$. Nous avons fait varier les trois taux vitaux afin d'examiner à quel point ils doivent être ajustés, soit indépendamment, soit conjointement, pour qu'une population stable $(\lambda$ =1) soit atteinte. Nous avons également évalué quelle composante de la fécondité (nombre de jeunes à

${ }^{1}$ University of British Columbia, Centre for Applied Conservation Research, Faculty of Forestry, ${ }^{2}$ Canadian Wildlife Service-Environment Canada, ${ }^{3}$ Wildlife Research Division, Washington Department of Fish and Wildlife, ${ }^{4}$ Wildlife Research Division-Environment Canada

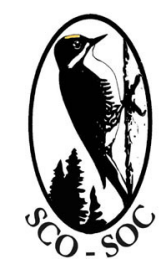

Sponsored by the Society of Canadian Ornithologists and Bird Studies Canada Parrainée par la Société des ornithologistes du Canada et Études d'oiseaux Canada

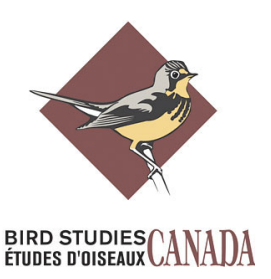


l'envol par œuf pondu ou intervalle entre les couvées) a le plus grand effet sur $\lambda$. L'estimation du taux de croissance laisse croire que la population d'Alouettes hausse-col de la sous-espèce strigata de l'État de Washington diminue rapidement $(\lambda=0,62 \pm 0,10)$ et que les sites locaux de nidification ne suffisent pas sans immigration. Les résultats de la simulation indiquent que la survie des adultes a davantage d'effet sur $\lambda$, suivie de la survie des jeunes et de la fécondité. Toutefois, pour que $\lambda$ atteigne la valeur 1 , la survie des adultes devait être augmentée de 0,47 à 0,85 , la survie des jeunes de 0,17 à 0,58 et la fécondité de 0,91 à 3,09 . Des augmentations du succès de nidification et des réductions de l'intervalle entre les couvées ont eu un effet semblable sur $\lambda$; cependant, $\lambda$ n'a pas atteint la valeur 1 même lorsque le succès de nidification était haussé à $100 \%$ ou lorsque l'intervalle entre les couvées était réduit à 1 jour. Ce n'est que lorsque les trois taux vitaux étaient haussés simultanément que $\lambda$ se rapprochait de la valeur 1 , sans avoir à grandement hausser chaque taux vital individuellement, de façon irréaliste. Nous concluons que les actions de conservation doivent cibler tous les taux vitaux ou plusieurs d'entre eux pour qu'elles soient efficaces. Les données présentées dans cet article et les efforts subséquents pour gérer l'Alouette hausse-col de la sousespèce strigata fourniront de l'information très utile pour gérer d'autres sous-espèces de l'Alouette haussecol et d'autres oiseaux chanteurs de prairie en déclin en Amérique du Nord.

Key Words: demography; Eremophila alpestris strigata; Life-Stage Simulation Analysis; population modeling; Streaked Horned Lark

\section{INTRODUCTION}

North American grassland birds have shown dramatic population declines over the last three decades (Askins 1993, Knopf 1994, Brennan and Kuvlesky 2005, Askins et al. 2007). This group has experienced a steeper and more wide-spread decline than other avian guilds (Knopf 1994). The loss and degradation of native prairie and agricultural grasslands are the main factors contributing to the declines (Herkert et al. 1996, Shustack et al. 2010). In most areas, habitat loss has exceeded $80 \%$ (Samson and Knopf 1994, Noss et al. 1995). As a result, active habitat and species management may be necessary in remaining grassland habitats to reverse population trends for grassland birds (Norment et al. 2010).

The Streaked Horned Lark (Eremophila alpestris strigata) is a ground-nesting grassland bird that prefers sparsely vegetated open grassland habitat (Beason 1995, Rogers 2000, Stinson 2005). Genetic data show that the Streaked Horned Lark is unique, isolated, and has little genetic diversity (Drovetski et al. 2005). The Streaked Horned Lark is listed as endangered by Washington State and is classified as a federal candidate for listing under the Endangered Species Act in the United States. In Canada, the subspecies is likely extirpated and is listed as endangered under the Species at Risk Act (Canadian Species at Risk Act 2002, c.29).
Historically, Streaked Horned Larks bred from southern British Columbia, through the Puget Trough in Washington and in the Willamette and Rogue River Valleys in Oregon (Fraser et al. 1999, Rogers 2000, Stinson 2005, Myers and Kreager 2010) (Fig. 1). The breeding range has contracted over time with local extirpation from former breeding sites across the range (Rogers 2000, Beauchesne and Cooper 2003, Stinson 2005). More than $90 \%$ of the original grasslands have been lost in the south Puget Sound as a result of development, intensification of agriculture, and the incursion of trees, shrubs, and non-native invasive species (such as Scotch broom [Cytisus scoparius]; Crawford and Hall 1997, Chappell et al. 2001, Stinson 2005). Population estimates indicate that there may be fewer than 1000 Streaked Horned Larks remaining (Pearson and Altman 2005).

One of the challenges in working with species at risk is that little information is available on vital rates, population ecology, and/or mechanisms of decline, yet they require conservation attention to reverse declining trends (O'Malley et al. 2009). Given limited resources for the management of declining species, it is helpful to evaluate the potential impacts of different management options on populations of interest in order to determine where efforts may be best directed to decrease or reverse population declines. The cost of field 
Fig. 1. Map showing current and historic range of Streaked Horned Larks. Historic range has contracted in the north and south, leaving only the middle portion of the range occupied currently. Stars represent currently occupied sites that were included in the study; circles represent currently occupied sites that were not included in the study; and triangles represent known historic breeding locations.

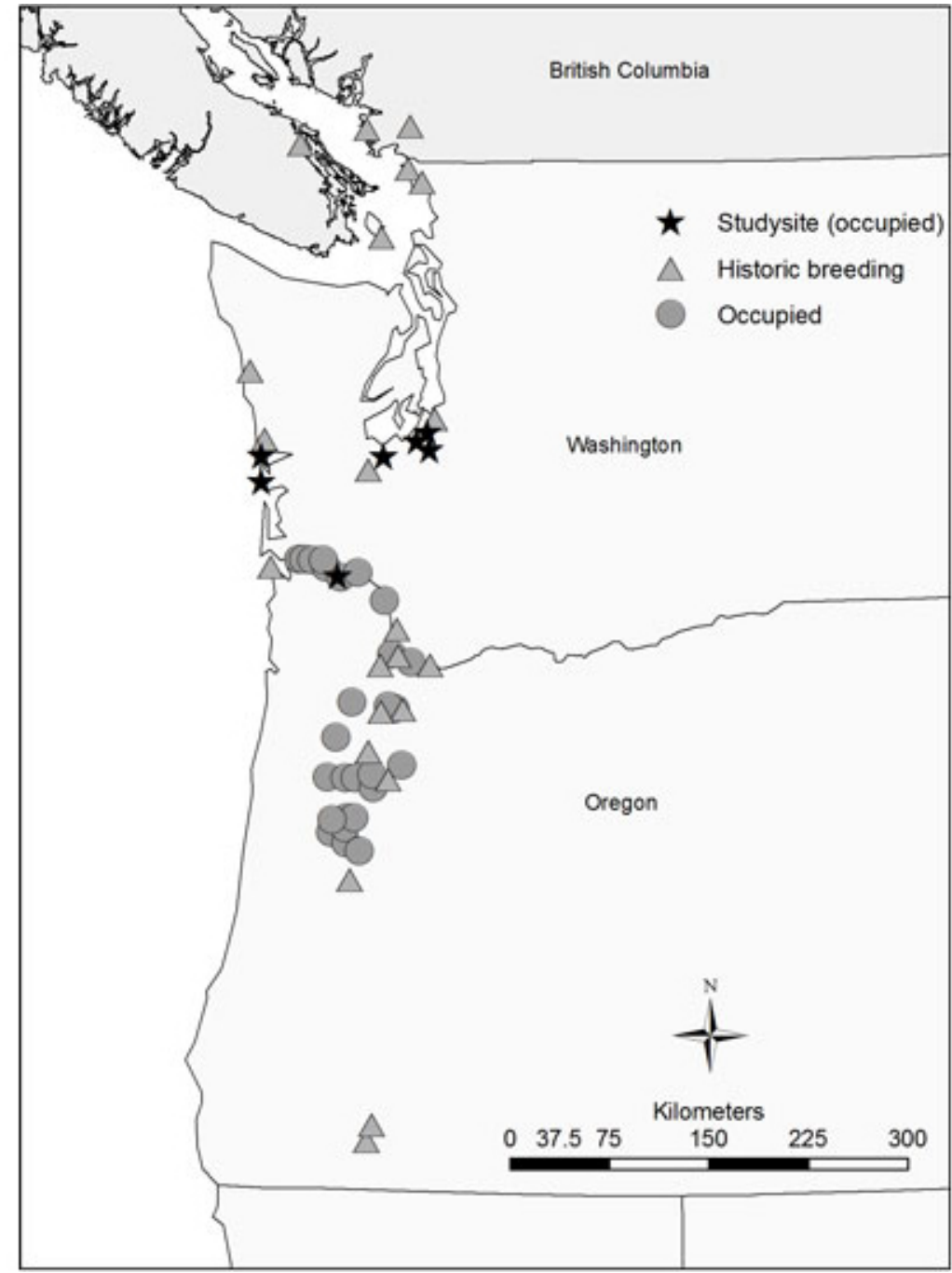

experiments and potential risk to sensitive species often prohibits direct tests of the effects of alternative management techniques (Heppell et al. 1994). Demographic modeling has become a common tool to evaluate alternative management actions for declining populations where experimentation may not be possible (Mills et al. 1999). When experimentation is not feasible, population models using age- or stage-based matrix models (Caswell 2001, Fieberg and Ellner 2001), or Life-Stage Simulation Analysis (LSA; Wisdom and Mills
1997, Wisdom et al. 2000) can be used to evaluate the relative importance of different vital rates on population growth rates $(\lambda)$ and prioritize vital rates for management. LSA has advantages when working with threatened or endangered species, in which case data may be limited because the results are relatively robust to the use of different probability distributions (Wisdom et al. 2000, Fieberg and Ellner 2001, Kaye and Pyke 2003), and a bounded uniform distribution can be used to model vital rates when the probability distributions are 
unknown (Sandercock et al. 2008). In addition, LSA can be used in the absence of data on age- or stagestructure in the population.

We conducted an LSA for the Streaked Horned Lark to evaluate which of three key vital rates (fecundity, adult survival, and juvenile survival) has the greatest influence on $\lambda$. Given an absence of data on the range of variation in vital rates that could be achieved by management, we examined the sensitivity of vital rates over their estimated range of variation, and we simulate changes in the three vital rates to examine how much they would need to change to achieve a stable or increasing Streaked Horned Lark population $(\lambda \geq 1)$. In addition, we evaluate which fecundity component (the number of fledglings per egg laid or renesting interval) has the greatest impact on $\lambda$ and examine the effect of varying all three vital rates simultaneously. Based on our simulations, we propose conservation actions that are likely to have the greatest impact on Streaked Horned Lark population growth and identify where further research is needed to facilitate Streaked Horned Lark recovery.

\section{METHODS}

\section{Study area}

In 1999 and 2000, the Washington Department of Fish and Wildlife conducted surveys of historically occupied sites and suitable sites for Streaked Horned Larks within the historic range, including large tracts of land dominated by grasses and forbs, Christmas tree farms and airfields in the San Juan Islands, north Puget Sound prairies, south Puget Sound prairies, Chehalis River Valley, outer coast of Grays Harbor and Pacific Counties, and the lower Columbia River west of Vancouver, Washington (MacLaren and Cummins 2000, Rogers 2000; R. E. Rogers, personal communication). Streaked Horned Larks were observed in 11 of 86 townships surveyed in 1999. An additional 25 townships were surveyed in 2000 along with the 11 occupied sites identified in the previous year, with no new occupied sites located and no changes in occupancy status. This study includes seven of these 11 occupied sites in Washington, USA; of the sites not included in this study, two are no longer occupied.

The study was conducted from 2002 to 2005 at seven sites that included grass- and forb-dominated habitats located in south Puget Sound prairies and airports, coastal Washington dune habitats, and islands in the lower Columbia River. Study sites, locations, and approximate number of pairs/sites observed during the study were: Olympia Airport $\left(46^{\circ} 58^{\prime} \mathrm{N}, 122^{\circ} 53^{\prime} \mathrm{W}\right) \approx 17$ pairs, $248 \mathrm{ha}$; 13th Division Prairie on Joint Base Lewis-McChord (47 $\left.01^{\prime} \mathrm{N}, 122^{\circ} 26^{\prime} \mathrm{W}\right) \approx 8-18$ pairs, 390 ha; Gray Army Airfield on Joint Base Lewis-McChord (47 ${ }^{\circ} 05^{\prime} \mathrm{N}$, $\left.122^{\circ} 34^{\prime} \mathrm{W}\right) \approx 31$ pairs, $162 \mathrm{ha}$; McChord Airfield on Joint Base Lews-McChord $\left(47^{\circ} 08^{\prime} \mathrm{N}, 122^{\circ}\right.$ $\left.28^{\prime} \mathrm{W}\right) \approx 30$ pairs, 309 ha; Damon Point $\left(46^{\circ} 56^{\prime} \mathrm{N}\right.$, $\left.124^{\circ} 06^{\prime} \mathrm{W}\right) \approx 17$ pairs, $141 \mathrm{ha}$; Midway Beach $\left(46^{\circ}\right.$ $\left.46^{\prime} \mathrm{N}, 124^{\circ} 05^{\prime} \mathrm{W}\right) \approx 21$ pairs, $193 \mathrm{ha}$; and Whites Island $\left(46^{\circ} 08^{\prime} \mathrm{N}, 123^{\circ} 18^{\prime} \mathrm{W}\right) \approx 8$ pairs, 41 ha. Study areas ranged in size from 7 to 249 ha, and elevation ranged from 3 to $122 \mathrm{~m}$ above sea level.

\section{Data collection}

The Streaked Horned Lark nesting season extended from April to mid-August. Nests were found during nest building, incubation, and nestling stages, and were located by observing adults leaving or approaching nests with and without nesting materials or carrying food, by flushing incubating or brooding adults, and by searching appropriate habitats. We recorded nest status (presence of parents, eggs, nestlings) every 3-5 days, more frequently near the expected hatch and fledging dates.

We captured adult birds using mist nets; captured birds were marked with unique color band combinations and morphological measurements were taken (wing chord, tarsus and weight). We conducted complete surveys of each study area at the beginning of each nesting season ( $\mathrm{n}=3$ surveys/ season minimum). For these surveys, transects were placed $150 \mathrm{~m}$ apart, and the entire area of suitable habitat was surveyed by walking slowly and stopping approximately every $100 \mathrm{~m}$ for $2 \mathrm{~min}$. The location of each bird detected was mapped to identify territories, and, within each territory, we attempted to determine whether each bird was banded and, for each banded bird, its unique color combination. For most sites, we were able to determine the banding status of nearly every bird present. We also monitored all birds observed when attempting to locate nests and during nest monitoring. Nestlings were banded between days 7 and 9 post-hatching or occasionally shortly after fledging. 


\section{Estimation of vital rates}

\section{Fecundity}

We calculated the annual production of fledglings per pair $(P)$ following the technique of Ricklefs and Bloom (1977) as:

$\mathrm{P}=\mathrm{F} * \mathrm{~B}$

Where $F$ is the number of young fledged/pair/day,

$F=C * S * I$,

$B$ is the length of the breeding season in days;

$B=30 \exp \left(-\sum \mathrm{p}_{i} \log _{e} p_{i}\right)$,

$p_{i}$ is the proportion of clutches laid by a population during month $i, C$ is clutch size, $S$ is breeding success (fledglings per egg laid), $I$ is the rate of nest initiation (clutches/pair/day);

$$
I=\frac{m}{p_{f}+m\left(p_{s} r_{s}+p_{f} r_{f}\right)}
$$

Where $m$ is the nest mortality rate (proportion of nests failing per day), $p_{s}$ is the probability that a nest successfully fledges at least one young;

$p_{s}=e^{-m T}$,

$p_{f}$ is the probability that a nest fails before fledging;

$p_{f}=1-p_{s}$,

$r_{s}$ is the delay before a new clutch is laid after successful fledging, $r_{f}$ is the delay before a new clutch is laid after nest failure, and $T=$ length of the nest cycle from clutch initiation to fledging (days).

Length of the breeding season $(B)$ was calculated using the proportion of active nests during each month of the breeding season to correct for the fact that breeding effort was not constant across all months; clutch size $(C)$ was calculated from nests that were observed with the same clutch size more than once (at least 1 day apart) during incubation; fledglings per egg laid $(S)$ was the proportion of eggs laid that produced a fledgling; daily nest mortality rate $(m)$ was calculated using midpoint method for the Mayfield (1975) estimator; multiple brood interval $\left(r_{s}\right)$ was calculated using the number of days between the successful fledging of a nest and the initiation of an additional brood; and replacement nest interval $\left(r_{f}\right)$ was calculated as the number of days between nest failure and the next clutch initiated by the same female. Nests were counted as successful if adults were seen with fledglings or if the nest was found empty with no signs of depredation on or after the expected fledging date. Nests with signs of depredation (included damaged eggs, blood, and/or feathers in or near the nest and nests found empty during incubation or during the nestling period when nestlings were too young to have fledged $[<8$ days post-hatching]) were counted as unsuccessful. To calculate multiple brood interval and the replacement nest interval, only nests with banded adults or on territories that were consistently monitored were included in the calculation. To estimate the number of female fledglings per female per year, annual production of fledglings per pair was divided by 2 , assuming an equal sex ratio at fledging.

\section{Adult and juvenile survival}

We used the Program MARK Version 5.1 (White and Burnham 1999) to estimate apparent survival rates $(\phi)$ corrected for the probability of resighting ( $p$; the probability the bird was seen given that it was alive) from live encounter data using the Cormack-Jolly-Seber model (Cormack 1964, Jolly 1965, Seber 1965). We did two separate analyses: one for adults only with sexes as two groups and another for juveniles with no distinction between sexes. Adult horned larks cannot be reliably aged in the field (Pyle 1997); therefore, we estimated apparent survival using a model that included sex (for adults only) but not age. The median c procedure in Program MARK (Cooch and White 2006) was used to assess goodness-of-fit of the global models $\left(\phi_{t^{*} s} p_{t^{*} s}\right)$ with two groups for males and females $(s)$ and time dependence $(t)$ for apparent survival and probability of encounter for adults. We used a 2 age-class model in MARK (Cooch and White 2006) to estimate juvenile survival, where juvenile survival was the probability of surviving the first year after fledging and adult survival was the probability of surviving in subsequent years. We were able to use only the simplest model for juvenile survival assuming constant survival without time dependence or sex because of small sample sizes 
and the simplest model that included sex for adults because of lack of fit.

\section{Population growth rate}

Population growth rate $(\lambda)$ was estimated using the following equation: $\lambda=F \phi_{j}+\phi_{a}$, where $F$ was the number of female fledglings produced per female per year (calculated by dividing the parameter $P$ explained above by 2 to estimate the number of female fledglings), $\phi_{j}$ was apparent juvenile survival, and $\phi_{a}$ was apparent adult female survival. We conducted a LSA to evaluate the relative contribution of the three vital rates to simulated variation in $\lambda$. Using randomly drawn sets of parameters (see below for an explanation of how the vital rate estimates were modeled to generate these parameters), we performed linear regressions with $\lambda$ as the dependent variable and the vital rates as the independent variables. We used the $r^{2}$-values to estimate the proportion of the variation in $\lambda$, which was explained by simulated variation in each vital rate. For our analysis, we assumed a closed population and treated parameters as independent.

We used a Monte Carlo simulation approach of 10,000 replicates to generate random sets of parameters. We used the estimates of variance generated by the program MARK to parameterize the distributions used to model adult and juvenile survival, and we used the mean and variance from the 4 years of fecundity estimates to parameterize the distributions used to model fecundity. We did not calculate annual $\lambda$ because the year-specific model for $\phi$ indicated lack of fit; rather, we used the estimated annual rates to calculate a single estimate of lambda. We used the 10,000 estimates of $\lambda$ to calculate the mean and standard deviation of $\lambda$, using the estimated range of the vital rates. Because years were pooled, it was not possible to separate process and sampling error (Gould and Nichols 1998). To explore the sensitivity of our results to the amount of variation in the parameter estimates and to changes in the probability distribution, we conducted six sets of simulations. First, we took random draws from a uniform distribution bounded by the $95 \%$ confidence intervals of the vital rate estimates. Then, we repeated the analysis using draws from uniform distributions bounded by the $80 \%$ and $50 \%$ confidence intervals of the vital rate estimates. Next, we modeled apparent survival of adults and juveniles using random draws from beta distributions using our estimates of variation for each vital rate. The beta distribution constrains the random variables between 0 and 1 and is therefore appropriate for modeling survival probabilities that must remain within these values (Morris and Doak 2002). To model fecundity, we also used a stretched beta distribution, a normal distribution, and a lognormal distribution. The stretched beta distribution is a rescaled beta distribution (Morris and Doak 2002). We defined the minimum fecundity value as 0 and the maximum value as 7.5 (maximum value was estimated by multiplying the maximum observed clutch size by the maximum observed number of broods/year and divided by 2 to estimate the number of female fledglings).

\section{Simulating changes in population growth}

For each of the three vital rates (adult female survival, juvenile survival, and fecundity), we determined the value that resulted in a stable population $(\lambda=1)$ by increasing one rate at a time by $10 \%$ (proportionally) and holding the other vital rates constant. After each $10 \%$ increase we reran the simulation described above to generate a new estimate of $\lambda$.

Potential management activities for Streaked Horned Larks may influence fecundity by increasing the number of fledglings produced per egg laid (hereafter called breeding success) or by decreasing renesting intervals. Breeding success can be increased by either decreasing nest failure or increasing hatching and fledging success, and decreasing renesting intervals is expected to result in more broods per season (numerous studies have shown that supplemental feeding can reduce renesting intervals; e.g., see Arcese and Smith 1988, Zanette et al. 2006). We used the technique of iterative increases of $10 \%$ described above to examine how increases in breeding success or decreases in renesting intervals affected $\lambda$. To accomplish this, we recalculated annual fecundity after each $10 \%$ increase in either breeding success or decrease in renesting interval and then used this new fecundity estimate in the Monte Carlo simulation of $\lambda$. We repeated this process, manipulating each variable independently until breeding success reached $100 \%$ and the renesting interval was 1 day.

To examine how much the three vital rates would need to increase in concert to achieve $\lambda \geq 1$, we reran the simulations described above but allowed the two rates to vary simultaneously. We evaluated every 
possible combination of $10 \%$ increase for the two rates (i.e., fecundity increased by $10 \%$, juvenile survival increased by $20 \%$, fecundity increased by $10 \%$, juvenile survival increased by $30 \%$, etc.). This process was repeated three times: once using the current empirical value for adult female survival, a second time with adult female survival raised by $10 \%$, and a third time with adult female survival raised to the level measured for Pallid Horned Larks (E.a. arcticola) in British Columbia (Camfield et al. 2010).

Our simulation results were virtually identical, regardless of the distribution selected and the degree of variation included (see Results); therefore, for the simulations described above, we used the beta distribution for adult and juvenile survival and the stretched beta distribution for fecundity. The beta distribution is the most commonly used distribution in modeling survival, and because the upper limit of the stretched beta distribution is constrained, it can reflect a more biologically realistic range for fecundity than other distributions that can generate unrealistically high estimates (Morris and Doak 2002).

All simulations were performed using the program $\mathrm{R}$, version 2.8.1, package random ( $\mathrm{R}$ Development Core Team 2008). Simulated estimates of $\lambda$ are normally distributed and are reported as means \pm $\mathrm{SD}$; all other means are reported $\pm \mathrm{SE}$.

\section{RESULTS}

During the course of this study, we monitored 257 Streaked Horned Lark nests and banded 58 adults (26 females, 32 males) and 88 juveniles. Our overall estimate of fecundity was $0.91 \pm 0.17$ female fledglings/female/year $(n=4$ years; 95\% CI 0.63 , 1.19). For estimates of the components of fecundity, see Table 1.

Goodness-of-fit tests indicated that there were insufficient data to fit a time-dependent model for apparent adult survival $(c=4.79)$. We therefore evaluated only one model for adult survival that included differences in sex $\left(\phi_{s}\right)$. The probability of encounter $(p)$ was 1 for adult males and females; therefore, we did not allow the probability of resighting to vary by sex. Sample size similarly constrained our choice of models to estimate apparent survival for juveniles; therefore, we used a reduced model with survival and probability of encounter held constant $(\phi p)$. Goodness-of-fit tests indicated only minor overdispersion $(\mathrm{c}=1.93$ and 1.51 for adults and juveniles, respectively). Apparent adult male survival was $0.55 \pm 0.08(n=$ $32 ; 95 \%$ CI $0.39,0.70)$, and apparent adult female survival was $0.47 \pm 0.08(n=26 ; 95 \%$ CI $0.32,0.63)$. Apparent juvenile survival was $0.17 \pm 0.05(n=88$; $95 \%$ CI $0.09,0.30)$; the probability of encounter for juveniles was $0.78 \pm 0.18$ (95\% CI 0.32, 0.96).

Our vital rate estimates derived over 4 years and over half of the Streaked Horned Lark breeding range indicate that the population is rapidly declining $(\lambda=0.62 \pm 0.10 ; 95 \%$ CI $0.47,0.79) ;<1 \%$ of the simulations predicted $\lambda>1$ (Fig. 2). The LSA revealed that, regardless of the degree of variance or the probability distribution used, adult survival consistently explained the highest proportion of the variation in $\lambda$, followed by juvenile survival and fecundity. The $r^{2}$-values for adult survival ranged from 0.59 to 0.69 , juvenile survival ranged from 0.22 to 0.24 , and fecundity ranged from 0.08 to 0.13 (Table 2). LSA results using the beta distribution for adult and juvenile survival, the stretched beta distribution for fecundity, and the full estimate of variance to parameterize the distributions are shown in Fig. 2.

When we increased each vital rate independently while holding the other two constant, it was necessary to increase female survival from 0.47 to 0.85 , juvenile survival from 0.17 to 0.58 , and fecundity from 0.91 to 3.09 , respectively, to achieve $\lambda=1$ (Fig. 3). Increasing breeding success to $100 \%$ and decreasing the renesting interval to 1 day did not raise $\lambda$ to 1 (Fig. 4). When both fecundity and juvenile survival were manipulated simultaneously to investigate their combined influence, $\lambda$ approached 1 only when juvenile survival and fecundity were each increased by more than $80 \%$ (Fig. 5a). When adult survival was increased by $10 \%$ (0.47 to 0.52 ), $\lambda$ approached 1 only when juvenile survival and fecundity were increased by over $60 \%$ (Fig. 5b). When adult survival was raised to the level measured for Pallid Horned Larks (0.65), $\lambda$ approached 1 when juvenile survival and fecundity were each increased by over $50 \%$ (Fig. 5c). 
Table 1. Estimates of the components of fecundity for Streaked Horned Larks in western Washington, USA.

\begin{tabular}{llll}
\hline \hline Fecundity component & Mean $\pm \mathrm{SE}$ & $n$ & $95 \% \mathrm{CI}$ \\
\hline Breeding season length (days) & $94.0 \pm 10.53$ & 4 years & $73.36,114.64$ \\
Clutch size (eggs) & $3.05 \pm 0.06$ & 135 clutches & $2.93,3.17$ \\
Fledglings per egg laid & $0.23 \pm 0.04$ & 123 nests & $0.15,0.31$ \\
Daily nest mortality rate & $0.058 \pm 0.003$ & 257 nests & $0.05,0.07$ \\
Probability at least one nestling fledges & $0.24 \pm 0.02$ & 257 nests & $0.20,0.28$ \\
Probability that a nest failed & $0.76 \pm 0.02$ & 257 nests & $0.72,0.80$ \\
Multiple brood interval (days) & 22 & 1 nest & $\mathrm{n} / \mathrm{a}$ \\
Replacement nest interval (days) & $22.25 \pm 4.25$ & 8 nests & $13.93,30.57$ \\
\hline
\end{tabular}

\section{DISCUSSION}

North American grassland birds have shown dramatic population declines over the last three decades (Askins 1993, Knopf 1994, Brennan and Kuvlesky 2005, Askins et al. 2007). Data from breeding bird surveys indicate that Horned Larks have declined throughout much of North America (Sauer et al. 2004), and the Washington Streaked Horned Lark population is no exception. Demographic models such as those used here are important tools in managing declining species when resources are limited and experimentation is not feasible. These models allow for the evaluation of different management options in order to determine where efforts may be best directed to decrease or reverse population declines. Our analyses suggest that Streaked Horned Lark populations are declining rapidly and appear to have reached a point where local sites are not sustainable without immigration. Although our analyses indicate that adult survival has the greatest influence on population growth (as is often the case; Pfister 1998), conservation actions that target only one vital rate are unlikely to lead to a stable population. However, if several vital rates are increased simultaneously, it may be possible for Streaked Horned Lark populations to stabilize or grow.

Our results are consistent with other evidence of Streaked Horned Lark population declines. Range contraction has been documented (Rogers 2000, Stinson 2005), and molecular data indicating remarkably low genetic diversity in Streaked Horned Larks suggest a severe genetic bottleneck was caused by range contraction (Drovetski et al. 2005). In addition, although there are no data on range-wide population trends for Streaked Horned Larks, territory mapping data from four sites in the Puget lowlands indicate that the average number of territories has decreased from 19.3/site in 2004 to 10.5 in 2007 (a total decrease of $45 \%$ over 3 years from 77 territories in 2004 to 42 in 2007; S. F. Pearson unpublished data). Although the point estimate of the rate of decline observed by mapping territories appears to be smaller than that predicted from our models, both indicate significant population declines. Because predictions of $\lambda$ based on estimates of vital rates do not often include estimates of immigration, they tend to be lower than predictions of $\lambda$ from count data (Stacey and Taper 1992, Sandercock et al. 2005, Fletcher et al. 2006).

Our estimate of $\lambda$ is a measure of whether the Streaked Horned Lark breeding sites in Washington are sustainable by local production of young without immigration. Although apparent survival rates are minimum estimates of survival because they do not make a distinction between permanent emigration and mortality (Lebreton et al. 1992), our estimate of juvenile survival for Streaked Horned Larks includes birds that dispersed throughout the study 
Fig. 2. Results of a LSA for Streaked Horned Larks in western Washington, USA, using beta distributions to model adult and juvenile survival and a stretched beta distribution for fecundity. Light gray diagonal lines are regression lines. Horizontal gray lines are shown at $\lambda=1$. The value at the intercept of the two lines gives the parameter value needed to support a stable population. Vertical solid and dashed lines show the estimated mean value for each vital rate and its standard errors. In all cases, the vital rate estimates fall to the left of the intercept of the two gray lines, indicating that the population is declining. The $r^{2}$-values show the proportion of the variation in $\lambda$ over all simulations that is explained by variation in each vital rate.

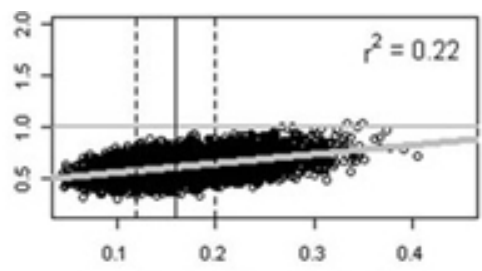

a. Juvenile survival
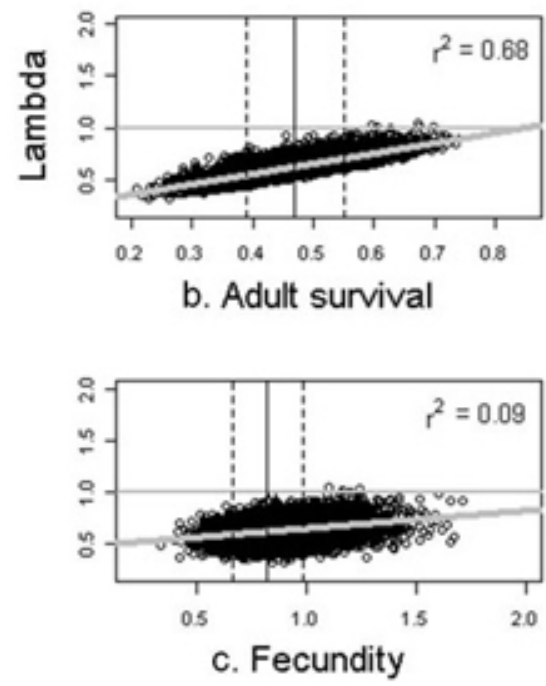

region. When dispersed individuals are removed from the sample, apparent juvenile survival drops to 0.09 (Pearson et al. 2008, Camfield et al. 2010), suggesting that there is considerable movement of juveniles among sites. Our ability to detect dispersal events is unusually high because extensive surveys were conducted throughout much of the range and because Streaked Horned Larks breed in distinct locations within a matrix of unsuitable forested habitat in western Washington. If some dispersal events were not detected, the estimate of juvenile survival may be slightly underestimated. In contrast to juvenile dispersal, adult dispersal appears to be uncommon as there were no instances of adult dispersal between breeding regions (e.g., between the Puget lowland and the Washington coast; Pearson et al. 2008). It is possible that individuals from the Willamette Valley population (the only portion of the breeding range of Streaked Horned Larks not included in this study) emigrate to Washington. However, this rescue effect would be modest given the low reproductive success reported for Streaked Horned Larks in the Willamette Valley $(14 \%, n=13$ nests; B. Altman, personal communication; $27 \%, n=16$ nests in $2007 ; 34 \%, n$ $=128$ nests [range 15-53\% across 4 sites], in 2008; R. Moore, Oregon State University, personal communication). Studies are needed to determine whether source populations exist and where they are located, and to insure that these populations are 
Table 2. Mean estimates of $\lambda$ and the percent of variation ( $r^{2}$-values) in $\lambda$ explained by adult and juvenile survival and fecundity using LSA for Streaked Horned Larks in western Washington, USA. ${ }^{\dagger}$

\begin{tabular}{lcccc}
\hline \hline Simulation & $\lambda$ & Juvenile Survival & Adult Survival & Fecundity \\
\hline A) Uniform, 95\% CI & $0.65 \pm 0.10$ & 0.23 & 0.62 & 0.13 \\
B) Uniform, 80\% CI & $0.62 \pm 0.07$ & 0.23 & 0.68 & 0.09 \\
C) Uniform, 50\% CI & $0.62 \pm 0.04$ & 0.23 & 0.69 & 0.08 \\
D) Beta and Stretched Beta & $0.62 \pm 0.10$ & 0.22 & 0.68 & 0.09 \\
E) Beta and Lognormal & $0.64 \pm 0.10$ & 0.24 & 0.59 & 0.16 \\
F) Beta and Normal & $0.64 \pm 0.08$ & 0.24 & 0.63 & 0.10
\end{tabular}

${ }^{\dagger}$ Rates were drawn from a uniform distribution bounded by the $95 \%$ confidence intervals for the vital rate estimates (A). Next, rates were drawn from a uniform distribution bounded by the $80 \%$ and $50 \%$ confidence intervals $(\mathrm{B}, \mathrm{C})$. The final three simulations used beta distributions to model adult and juvenile survival and a stretched beta distribution for fecundity (D), a lognormal distribution for fecundity $(\mathrm{E})$, and a normal distribution for fecundity $(\mathrm{F})$.

maintained because it is clear that it will be difficult to sustain the Streaked Horned Lark population in Washington without immigration.

Although survival is difficult to influence through management (Porneluzi and Faaborg 1999, Anders and Marshall 2005, Knutson et al. 2006), it is the vital rate most likely to influence Streaked Horned Lark population growth. Thus, we need to consider the factors that likely influence Streaked Horned Lark survival in both the breeding and nonbreeding seasons and explore conservation actions to reduce their impacts. Horned Larks are the most commonly reported species involved in bird-aircraft collisions in the United States, representing almost $13 \%$ of all reported bird strikes (BASH 2009), and Streaked Horned Larks nest at five airports in Washington and one in Oregon. Improving nesting habitat away from active runways may reduce collisions and improve adult survival if enough suitable habitat exists away from the runway. Alternative approaches to reduce airstrikes should also be investigated. Additional habitat improvements include increasing food availability and quality and identifying and enhancing habitats needed to escape and/or detect predators and identifying and reducing the number of predators.
Apparent survival of adult songbirds is often lowest during the over-winter period (Powell et al. 2000, Sillett and Holmes 2002). Nearly all of the Streaked Horned Larks that breed in the Puget Lowlands of Washington over-winter along the lower Columbia River, the Washington coast, and the Willamette Valley of Oregon (Pearson et al. 2005). Unfortunately, little information exists about overwintering habitat selection, what constitutes highquality winter habitat, and the causes of mortality during the nonbreeding season.

Although our models suggest that fecundity has a smaller influence on $\lambda$ than survival rates, it may be the vital rate with the greatest potential for change in response to management actions. When compared with Pallid Horned Larks in British Columbia, the fecundity of Streaked Horned Larks in Washington appears to be quite low (Camfield et al. 2010). In British Columbia, fecundity was 1.75 female fledglings/female/year compared with 0.91 in Washington. For the Streaked Horned Lark, all of the components of fecundity (with the exception of breeding season length) were depressed compared with Pallid Horned Larks, suggesting that all components of fecundity could be improved. Scheduling land management and other human 
Fig. 3. Predicted values of $\lambda$ for Streaked Horned Larks in western Washington, USA, with successive increases in each vital rate. Each point represents a $10 \%$ increase in the vital rate. Only one vital rate was manipulated at a time. Error bars represent $\pm 1 \mathrm{SD}$. The solid horizontal line represents $\lambda=1$.

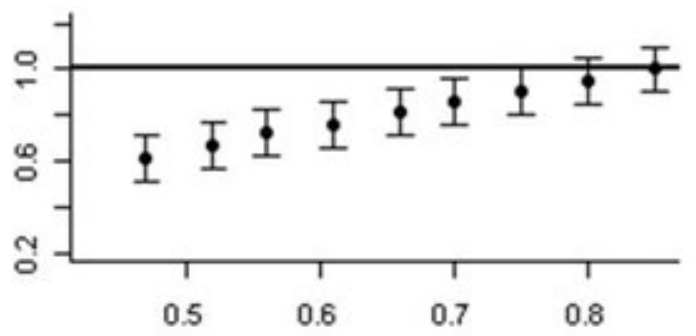

a. Adult survival

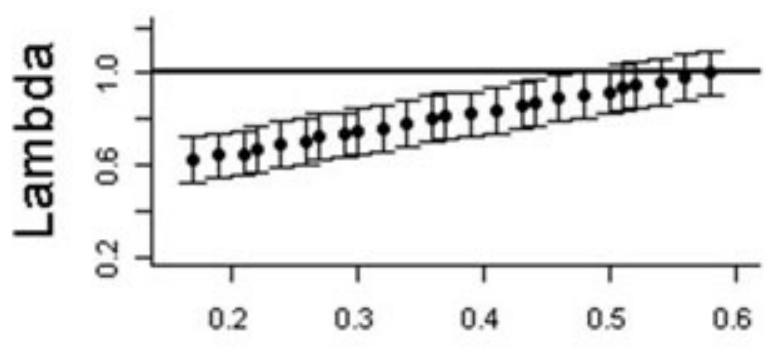

b. Juvenile survival

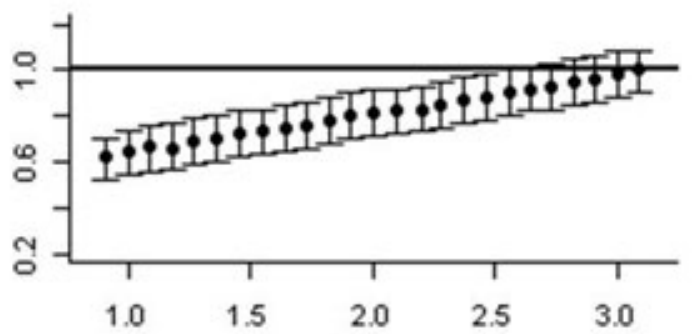

c. Fecundity

activities outside peak nesting periods is a relatively simple and inexpensive way to reduce accidental nest loss. For example, mowing regimens at airport breeding sites in Washington (Olympia Airport and Gray Army Airfield) have already been adjusted to reduce the potential for destroying nests. Given high values for juvenile survival, and assuming that density-dependent effects would be weak due to small population sizes, improvements in fecundity could have large cascading effects on population growth rates.

Conservation activities that target breeding success (number of fledglings per egg laid) or renesting intervals will have similar impacts on annual fecundity (Fig. 4). Some information exists on the habitat features important to territorial males and successful nesting (Pearson and Hopey 2004) and should be used to inform restoration objectives. Streaked Horned Lark eggs throughout Washington have low hatchability; only $83 \%$ of the eggs that survive the incubation period hatch (Camfield et al. 2010). Streaked Horned Larks have low genetic diversity compared with other subspecies of Horned Larks (Drovetsky et al. 2006), and the low hatchability of eggs may be the result of inbreeding depression. In addition, whereas horned lark renesting intervals typically range from 2 to 6 days 
Fig. 4. Predicted values of fecundity and $\lambda$ for Streaked Horned Larks in western Washington, USA, with successive increases in breeding success (the number of fledglings produced per egg laid; a) and successive decreases in the renesting interval (b). Each point represents a $10 \%$ change in the rate. Simulations were conducted until breeding success equaled $100 \%$ and the renesting interval equaled 1 day. Only one rate was manipulated at a time; error bars represent $\pm 1 \mathrm{SD}$. The solid horizontal line represents $\lambda=1$.
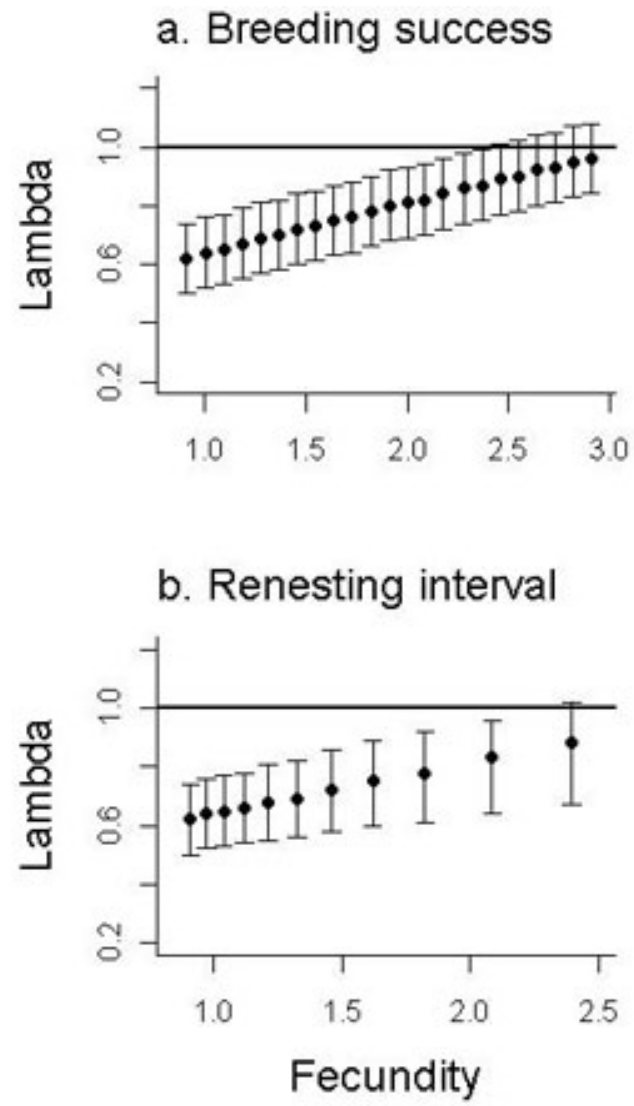

(Beason 1995), Streaked Horned Larks in Washington had average renesting intervals of 22 days (minimum interval was 10 days). Improving the availability of naturally occurring high-quality food resources or supplemental feeding can reduce renesting intervals and increase clutch size in songbirds (Arcese and Smith 1988, Zanette et al. 2006). Fecundity can also be improved by decreasing total nest failure. The majority of nest mortality is caused by predators, although human activities that prevent females from returning to their nests for extended periods may lead to nest abandonment (Pearson et al. 2005, 2008). If successful, predator control and the use of nest exclosures will increase breeding success by reducing nest depredation (Rimmer and Deblinger 1990, Pauliny et al. 2008). Nest exclosures were used successfully to exclude predators from snowy plover nests, and initial attempts with Streaked Horned Larks have had mixed results (S. F. Pearson, personal observation). Where the ranges of the two species overlap, collaborating with Snowy Plover management efforts may reduce the expense and hasten the recovery efforts of Streaked Horned Larks.

Future research should concentrate on evaluating over-winter habitat requirements for Streaked Horned Larks, identifying causes of adult mortality and evaluating methods for improving fecundity. 
Fig. 5. Predicted values of $\lambda$ for Streaked Horned Larks in western Washington, USA, as fecundity and juvenile survival are simultaneously increased by increments of $10 \%$ starting with current empirical levels of 0.91 for fecundity and 0.17 for juvenile survival. The $\mathrm{x}$ and $\mathrm{y}$ axes show the value for fecundity and juvenile survival after each iteration. Adult survival of female Streaked Horned Larks was held constant at its current empirical level of 0.47 (a), increased by $10 \%$ to 0.52 (b), and increased to 0.65 (c), the level of Pallid Horned Larks in northern British Columbia, Canada (Camfield et al. 2010).

\section{a. Adult survival (0.47)}

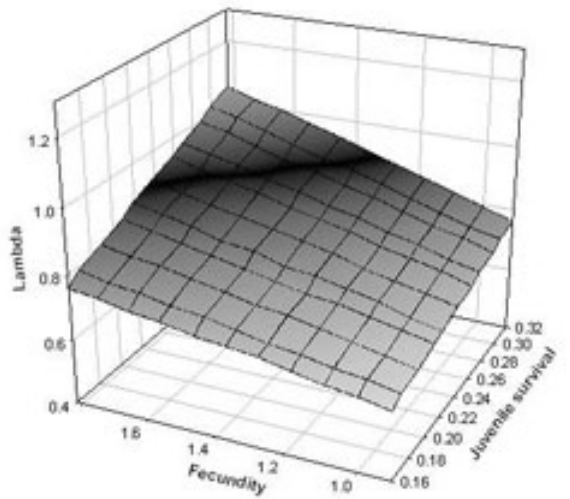

b. Adult survival $(0.52)$

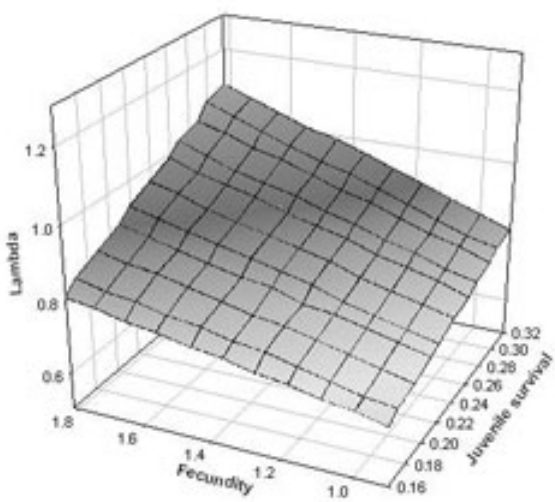

c. Adult survival $(0.65)$

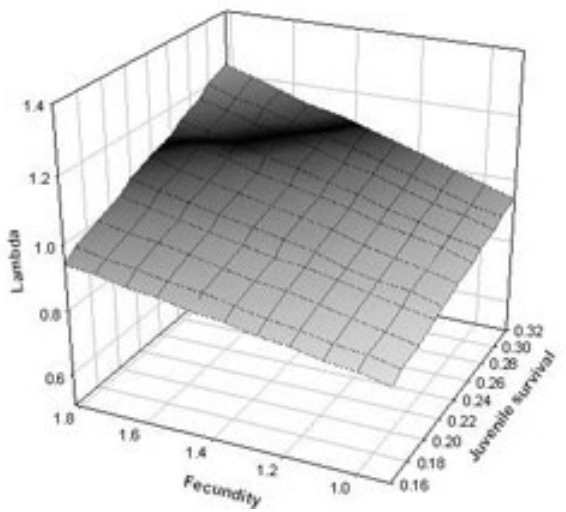


New studies are needed to determine where potential source populations are located, and continued studies of marked birds are necessary to provide estimates of adult and natal dispersal and movements of adults following nest failure.

\section{CONCLUSION}

Given that the loss and degradation of native prairie and agricultural grasslands are the main factors contributing to the declines in grassland songbirds (Herkert et al. 1996, Shustack et al. 2010), the most immediate conservation action that managers can take is to preserve existing habitat and maintain or improve vegetation structure and composition within existing occupied habitat patches. However, if preserved or restored habitats do not support stable populations in the absence of immigration, as appears to be the case for Streaked Horned Larks in Washington, management must also focus on improving demographic rates. We show that targeting only a single vial rate is not likely to increase $\lambda$ above 1 ; therefore, we recommend targeting multiple vital rates by prioritizing actions such as predator control and methods for improving fecundity such as the use of nest exclosures. However, such management actions need to be carefully evaluated through experimentation and monitoring to determine their efficacy. Surprisingly few studies have collected detailed demographic data for horned larks despite their ubiquitous presence across the continent. Horned larks in North America are declining through much of their range (Sauer et al. 2004); the baseline data presented here and subsequent efforts to manage Streaked Horned Larks will provide valuable information for management of other declining Horned Lark subspecies and other grassland songbirds across North America.

Responses to this article can be read online at: http://www.ace-eco.org/vol6/iss2/art4/responses/

\section{Acknowledgments:}

We thank C. Ames, H. Anderson, T. Chestnut, A. Emlen, H. Halbritter, M. Mossop, M. Pett, L. Sampson, C. Sundstrom, M. Tomlinson, and L. Wenn for field assistance and are particularly indebted to A. Clason, M. Hopey, and M. Martin for their help over multiple years. Funding was provided by the
Natural Sciences and Engineering Research Council of Canada (NSERC; postgraduate scholarship), the Northern Scientific Training Program, American Ornithologists'Union (Student Research Award), Environment Canada (Science Horizons grant), University of British Columbia (graduate fellowship) to A.F. Camfield; NSERC Discovery and Northern Research Supplement and Environment Canada grants to K. Martin; U.S. Fish and Wildlife Service, Joint Base Lewis-McChord, The Nature Conservancy, and Washington Departments of Fish and Wildlife, Natural Resources and Transportation to S.F. Pearson. We also thank Joint Base Lewis-McChord, Shelton Airport, Olympia Airport, Washington State Parks, and U.S. Fish and Wildlife Service for allowing access to the study sites. B. Altman, J. Citta, M. Drever, D. Green, S. Hinch, D. Irwin, R. Moore, and $B$. Sandercock and several anonymous reviewers provided valuable comments on earlier drafts.

\section{LITERATURE CITED}

Anders, A. D., and M. R. Marshall. 2005. Increasing the accuracy of productivity and survival estimates in assessing landbird population status. Conservation Biology 19:66-74. http://dx.doi.org/10.1111/j.1523 $-1739.2005 .00543 . \mathrm{x}$

Arcese, P., and J. N. M. Smith. 1988. Effects of population density and supplemental food on reproduction in song sparrows. Journal of Animal Ecology 57:119-136. http://dx.doi.org/10.2307/4768

Askins, R. A. 1993. Population trends in grassland, shrubland, and forest birds in eastern North America. Current Ornithology 11:1-34.

Askins, R. A., F. Chavez-Ramirez, B. C. Dale, C. A. Haas, J. R. Herkert, F. L. Knopf, and P. D. Vickery. 2007. Conservation of grassland birds in North America: Understanding ecological processes in different regions. Ornithological Monographs 124:1-46.

[BASH] Bird/Wildlife Aircraft Strike Hazard Team. 2009. Top 50 USAF wildlife strikes by cost. Aviation Safety Division, U.S. Air Force. [online] URL: http://www.afsc.af.mil/shared/media/document/ AFD-080130-040.pdf 
Beason, R. C. 1995. Horned Lark (Eremophila alpestris). In A. Poole and F. Gill, editors. The birds of NorthAmerica, no. 195. The Academy of Natural Sciences, Philadelphia, Pennsylvania, USA; and The American Ornithologists' Union, Washington, D.C., USA.

Beauchesne, S., and J. Cooper. 2003. COSEWIC status report on the horned lark strigata subspecies Eremophila alpestris strigata. Status report prepared for the Committee on the Status of Endangered Wildlife in Canada. COSEWIC Secretariat c/o Canadian Wildlife Service, Environment Canada.

Brennan, L. A., and W. P. Kuvlesky. 2005. North American grassland birds: an unfolding conservation crisis? Journal of Wildlife Management 69:1-13. http://dx.doi.org/10.2193/0022-541X(2005)069<0001: NAGBAU>2.0.CO;2

Burnham, K. P., and D. R. Anderson. 2002. Model selection and multimodel inference: a practical information-theoretic approach. Springer-Verlag, New York, New York, USA.

Camfield, A. F., S. F. Pearson, and K. Martin. 2010. Life history variation between high and low elevation subspecies of horned larks Eremophila spp. Journal of Avian Biology 41:273-281.

Caswell, H. 2001. Matrix population models: construction, analysis and interpretation. Sinauer, Sunderland, Massachusetts, USA.

Chappell, C. B., M. S. Mohn Gee, B. Stephens, R. Crawford, and S. Farone. 2001. Distribution and decline of native grasslands and oak woodlands in the Puget lowland and Willamette Valley ecoregions, Washington. In S. H. Reichard, P. W. Dunwiddie, J. G. Gamon, A. R. Kruckeberg, and D. L. Salstrom, editors. Conservation of Washington's native plants and ecosystems. Washington Native Plant Society, Seattle, Washington, USA.

Cooch, E. G., and G. W. White. 2006. Using MARK: a gentle introduction, 2nd ed. [online] URL: http:// www.Phidot.Org/software/mark/docs/book/

Cormack, R. M. 1964. Estimates of survival from the sighting of marked animals. Biometrika 51:429-438.

Crawford, R. C., and H. Hall. 1997. Changes in the south Puget prairie landscape. In P. Dunn and K.
Ewing, editors. Ecology and conservation of the south Puget sound prairie landscape. The Nature Conservancy, Seattle, Washington, USA.

Drovetski, S. V., S. F. Pearson, and S. Rohwer. 2005. Streaked Horned Lark Eremophila alpestris strigata has distinct mitochondrial DNA. Conservation Genetics 6:875-883. http://dx.doi.org /10.1007/s10592-005-9074-9

Fieberg, J., and S. P. Ellner. 2001. Stochastic matrix models for conservation and management: a comparative review of methods. Ecology Letters 4:244-266. http://dx.doi.org/10.1046/j.1461-0248.2 001.00202.x

Fletcher, R. J., R. R. Koford, and D. A. Seaman. 2006. Critical demographic parameters for declining songbirds breeding in restored grasslands. Journal of Wildlife Management 70:145-157. http:/ /dx.doi.org/10.2193/0022-541X(2006)70[145:CDPFDS] 2.0.CO;2

Fraser, D. F., W. L. Harper, S. G. Cannings, and J. M. Cooper. 1999. Rare birds of British Columbia. Ministry of Environment, Lands and Parks, Wildlife Branch and Resources Inventory Branch, Victoria, BC, Canada.

Gould, W., and J. Nichols. 1998. Estimation of temporal variability of survival in animal populations. Ecology 79:2531-2538. http://dx.doi.o $\mathrm{rg} / 10.1890 / 0012-9658(1998) 079[2531:$ EOTVOS]2.0. $\mathrm{CO} ; 2$

Heppell, S. S., J. R. Walters, and L. B. Crowder. 1994. Evaluating management alternatives for redcockaded woodpeckers: a modeling approach. Journal of Wildlife Management 58:479-487. http:/ /dx.doi.org/10.2307/3809319

Herkert, J., D. W. Samplea, and R. E. Warner. 1996. Management of Midwestern grassland landscapes for the conservation of migratory birds. Pages 89-116 in F. R. Thompson, III, editor. Management of Midwestern landscapes for the conservation of migratory birds. U.S. Forest Service General Technical Report NC-187.

Jolly, G. M. 1965. Explicit estimates from capturerecapture data with both death and immigrationstochastic model. Biometrika 52:225-247.

Kaye, T. N., and D. A. Pyke. 2003. The effect of stochastic technique on estimates of population 
viability from transition matrix models. Ecology 84:1464-1476. http://dx.doi.org/10.1890/0012-9658 (2003)084[1464:TEOSTO]2.0.CO;2

Knopf, F. L. 1994. Avian assemblages on altered grasslands. Studies in Avian Biology 15:247-257.

Knutson, M. G., L. A. Powell, R. K. Hines, M. A. Friberg, and G. J. Niemi. 2006. An assessment of bird habitat quality using population growth rates. Condor 108:301-314. http://dx.doi.org/10.1650/001 0-5422(2006)108[301:AAOBHQ]2.0.CO;2

Lebreton, J. D., K. P. Burnham, J. Clobert, and D. R. Anderson. 1992. Modeling survival and testing biological hypotheses using marked animals: a unified approach with case-studies. Ecological Monographs 62:67-118. http://dx.doi.org/10.2307/ $\underline{2937171}$

MacLaren, P. A., and E. B. Cummins. 2000. Streaked Horned Lark Surveys in Western Washington. Report funded by USFWS.

Mayfield, H. F. 1975. Suggestions for calculating nest success. Wilson Bulletin 87:456-466.

Mills, L. S., D. F. Doak, and M. J. Wisdom. 1999. Reliability of conservation actions based on elasticity analysis of matrix models. Conservation Biology 13:815-829. http://dx.doi.org/10.1046/j.15 23-1739.1999.98232.x

Morris, W. F., and D. F. Doak. 2002. Quantitative conservation biology: theory and practice of population viability analysis. Sinauer, Sunderland, Massachusetts, USA.

Myers, A. M., and D. A. Kreager. 2010. Declining and state sensitive bird species breeding in Willamette Valley grasslands: 2008/09 status update. Oregon Department of Fish and Wildlife, Salem, Oregon, USA.

Norment, C. J., M. C. Runge, and M. R. Morgan. 2010. Breeding biology of grassland birds in western New York: conservation and management implications. Avian Conservation and Ecology 5:3. http://dx.doi.org/10.5751/ACE-00399-050203

Noss, R. F., E. T. Laroe, and J. M. Scott. 1995. Endangered ecosystems of the United States: a preliminary assessment of loss and degradation.
National Biological Service, U.S. Department of the Interior, Report No. 0611-R-01 (MF), Washington, D.C., USA

O'Malley, R., A. S. Marsh, and C. Negra. 2009. Closing the environmental data gap. Issues in Science and Technology 25:69-74.

Pauliny, A., M. Larsson, and D. Blomqvist. 2008. Nest predation management: effects on reproductive success in endangered shorebirds. Journal of Wildlife Management 72:1579-1583.

Pearson, S. F., and B. Altman. 2005. Range-wide Streaked Horned Lark (Eremophila alpestris strigata) assessment and preliminary conservation strategy. Washington Department of Fish and Wildlife, Olympia, Washington, USA.

Pearson, S. F., A. F. Camfield, and K. Martin. 2008. Streaked Horned Lark (Eremophila alpestris strigata) fecundity, survival, population growth and site fidelity: research progress report. Washington Department of Fish and Wildlife, Wildlife Science Division, Olympia, Washington, USA.

Pearson, S. F., and M. Hopey. 2004. Streaked Horned Lark inventory, nesting success and habitat selection in the Puget lowlands of Washington. Natural Areas Program Report 2004-1. Washington Department of Natural Resources, Olympia, Washington, USA.

Pearson, S. F., M. Hopey, W. D. Robinson, and R. Moore. 2005. Range, abundance and movement patterns of wintering Streaked Horned Larks in Oregon and Washington. Natural Areas Program Report 2005-2. Washington Department of Natural Resources, Olympia, Washington, USA.

Pfister, C. A. 1998. Patterns of variance in stagestructured populations: evolutionary predictions and ecological implications. Proceedings of the National Academy of Sciences USA 95:213-218.

Porneluzi, P. A., and J. Faaborg. 1999. Season-long fecundity, survival, and viability of ovenbirds in fragmented and unfragmented landscapes. Conservation Biology 13:1151-1161. http://dx.doi.org/10.1046/j. 1523-1739.1999.98455.x

Powell, L. A., J. D. Lang, M. J. Conroy, and D. G. Krementz. 2000. Effects of forest management on 
density, survival, and population growth of wood thrushes. Journal of Wildlife Management 64:11-23. http://dx.doi.org/10.2307/3802970

Pyle, P. 1997. Identification guide to North American birds. Part 1: Columbidae to Ploceidae. Slate Creek Press, Bolinas, California, USA.

R Development Core Team. 2008. R: A language and environment for statistical computing. R Foundation for Statistical Computing, Vienna, Austria. [online] URL: http://www.R-project.org

Ricklefs, R. E., and G. Bloom. 1977. Components of avian breeding productivity. The Auk 94:86-96.

Rimmer, D. W., and R. D. Deblinger. 1990. Use of predator exclosures to protect piping plover nests. Journal of Field Ornithology 61:217-223.

Rogers, R. E. 2000. The status and microhabitat selection of Streaked Horned Lark, western bluebird, Oregon vesper sparrow, and western meadow lark in western Washington. Thesis. The Evergreen State College, Olympia, Washington, USA.

Samson, F., and F. Knopf. 1994. Prairie conservation in North America. BioScience 44:418-421. http://dx.doi.org/10.2307/1312365

Sandercock, B. K., W. E. Jensen, C. K. Williams, and R. D. Applegate. 2008. Demographic sensitivity of population change in northern bobwhite. Journal of Wildlife Management 72:970-982. http://dx.doi.o $\mathrm{rg} / 10.2193 / 2007-124$

Sandercock, B. K., K. Martin, and S. J. Hannon. 2005. Life history strategies in extreme environments: comparative demography of Arctic and alpine Ptarmigan. Ecology 86:2176-2186. http: //dx.doi.org/10.1890/04-0563

Sauer, J. R., J. E. Hines, and J. Fallon. 2004. The North American Breeding Bird Survey, Results and Analysis 1966-2003, version 2004.1. USGS Patuxent Wildlife Research Center, Laurel, Maryland, USA.

Seber, G. A. F. 1965. A note on multiple-recapture census. Biometrika 52:249-259.

Shustack, D. P., A. M. Strong, and T. M. Donovan. 2010. Habitat use patterns of Bobolinks and
Savannah Sparrows in the northeastern United States. Avian Conservation and Ecology 5:11. http: //dx.doi.org/10.5751/ACE-00423-050211

Sillett, T. S., and R. T. Holmes. 2002. Variation in survivorship of a migratory songbird throughout its annual cycle. Journal of Animal Ecology 71:296-308. http://dx.doi.org/10.1046/j.1365-2656 $.2002 .00599 . \mathrm{x}$

Stacey, P. B., and M. Taper. 1992. Environmental variation and the persistence of small populations. Ecological Applications 2:18-29. http://dx.doi.org/ $\underline{10.2307 / 1941886}$

Stinson, D. W. 2005. Draft Washington State status report for the mazama pocket gopher, Streaked Horned Lark, and Taylor's checkerspot. Washington Department of Fish and Wildlife, Olympia, Washington, USA.

White, G. C., and K. P. Burnham. 1999. Program MARK: survival estimation from populations of marked animals. Bird Study 46:120-139.

Wisdom, M. J., and L. S. Mills. 1997. Sensitivity analysis to guide population recovery: prairiechickens as an example. Journal of Wildlife Management 61:302-312. http://dx.doi.org/10.2307 $\underline{13802585}$

Wisdom, M. J., L. S. Mills, and D. F. Doak. 2000. Life stage simulation analysis: Estimating vital-rate effects on population growth for conservation. Ecology 81:628-641. http://dx.doi.org/10.1890/001 2-9658(2000)081[0628:LSSAEV]2.0.CO;2

Zanette, L., M. Clinchy, and J. N. M. Smith. 2006. Food and predators affect egg production in song sparrows. Ecology 87:2459-2467. http://dx.doi.org/ 10.1890/0012-9658(2006)87[2459:FAPAEP]2.0.CO;2 